\title{
Protective Effect of Ginger Extract against Aspirin Induced Acute Gastric, Renal and Hepatic Damage in Rats
}

\author{
Nasr Elsayed Nasr ${ }^{1 *}$, Walied $\mathrm{Abdo}^{2}$, Wael Goda ${ }^{3}$ and Mostafa Elmadawy ${ }^{4}$ \\ Departments of Biochemistry ${ }^{1}$, Pathology ${ }^{2}$ and Forensic Medicine and Toxicology ${ }^{4}$, Faculty of Veterinary Medicine, \\ Kafrelsheikh University, Egypt, \\ ${ }^{3}$ Department of Clinical Pathology, Faculty of Veterinary Medicine, Damanhour University, Egypt
}

ARTICLE INFO

Article history:

Received 20 June 2017

Accepted 17 August 2017

Keywords:

Aspirin;

Ginger;

Gastric ulcer:
Papillary necrosis.

\begin{abstract}
A B S T R A C T
The present study aimed to investigate the role of ginger in the prevention of aspirin-induced gastric and hepato-renal injury. Forty rats were distributed into 4 groups: normal control, aspirin, ginger control, and ginger plus aspirin. The normal control group was gavaged with saline for 7 days. The second group similarly treated with control except it was administered about $150 \mathrm{mg} / \mathrm{kg}$ aspirin on the $7^{\text {th }}$ day. The animal of third group was treated with ginger orally for 7 days. The forth group was similarly treated as the previous group except it was administrated aspirin on the $7^{\text {th }}$ day. The results of the biochemical analysis reported that ginger supplement preserved liver and kidney function serum markers close to normal. Also, histopathological findings demonstrated that pretreatment with ginger reversed aspirin-induced gastric, renal and hepatic tissues damage. Additionally, assessment of oxidative stress in tissues homogenates revealed that pretreatment with ginger attenuates significantly $(\mathrm{p}<0.001)$ lipid peroxidation marker malondialdehyde (MDA) and preserved the anti-oxidant enzymes superoxide dismutase (SOD) and catalase (CAT) in the three investigated organs. It could be concluded that ginger pretreatment attenuates the aspirin-induced gastric and hepato-renal lesions via inhibiting the resultant oxidative stress.
\end{abstract}

\section{Introduction}

Aspirin, also known as acetylsalicylic acid (ASA), is a salicylate medication, worldwide popular used painkiller, antipyretic and anti-inflammatory. Aspirin is part of a group of nonsteroidal anti-inflammatory drugs (NSAIDs). Unlike most of NSAIDS, Aspirin irreversibly inhibits the cyclooxygenase 1 (COX-1) platelets variant more than the COX-2 inflammatory variant of the enzyme. Therefore, Aspirin is the "gold standard" long antiplatelet agent, at low daily doses, to help prevent heart attacks, strokes, and thrombi formation in people at high risk of developing blood clots ${ }^{[1]}$. However, the main side effects of aspirin are gastrointestinal ulcers and stomach bleeding particularly with higher doses. Though daily aspirin therapy can help prevent a clot-related stroke, the risk of a bleeding stroke is increased ${ }^{[2]}$. In the meantime, excessive administration of combined analgesics contained aspirin or other NSAIDs leads to kidney injury. The specific kidney injuries induced by analgesics are renal papillary

\footnotetext{
* Corresponding author.

E-mail address: nasr_157@yahoo.com
}

Interestingly, NSAIDs, in addition to antimicrobial agents, are the most common causes of drug induced liver injury (DILI) ${ }^{[4-6]}$. Moreover, NSAIDs-induced acute combined hepato-nephrotoxicity has been reported $[7,8]$. Accordingly, the adverse effect of aspirin and its related NSAIDs triggered the research for traditional medicinal plants.

Ginger (Zingiber officinale Roscoe, family: Zingiberaceae) originated in South-East Asia and is the most common spice, used all over the world ${ }^{[9]}$. The main constituents of ginger are zingerone, shogaols, and gingerols. Ginger pharmacological properties are varied including antioxidant [10], anti-inflammatory [11], anticancer ${ }^{[12]}$, and antimicrobial activities. The current study was constructed to evaluate the comprehensive ameliorative effect of ginger against aspirin induced lesions on stomach, kidney and liver.

\section{Materials and methods}

Animals and Study design

Forty male Wistar albino rats (150-200 g) were obtained from experimental animal farm within Kafrelsheikh necrosis and chronic interstitial nephritis ${ }^{[3]}$. 
University. For 7 days of adaptation, all animals were fed on standard laboratory diet and water ad libitum and kept in cages at a temperature of $20^{\circ} \mathrm{C}$ with a 12-hour (h) dark/light cycle before and during experiments. This study was approved by Kaferelsheikh University, Faculty of Veterinary Medicine Ethical Committee.

After acclimatization, animals were divided into four groups, each of 10 animals, with different pre-treatments for 7 days, as follows: normal control group (C) and aspirin group (A) were left on normal water and food without any treatment. Ginger dried powder was purchased from local market of Herbs and Medicinal plants. Authentication of the plant was confirmed by staff members of Botany Department, Faculty of Science, Kafrelsheikh University, Kafr Elsheikh, Egypt. Ginger control group (G) and ginger pretreated group $(\mathrm{A}+\mathrm{G})$ were given ginger $(100 \mathrm{mg} / \mathrm{kg}$ body weight daily) by gavages ${ }^{[13]}$. On day 7,12 hours before aspirin administration $(150 \mathrm{mg} / \mathrm{kg})^{[13]}$, rats were deprived of food and water while coprophagy was avoided but had free access to water $2 \mathrm{~h}$ before aspirin administration. Then, gastric, kidney and liver lesions were induced by administration of aspirin $(150 \mathrm{mg} / \mathrm{kg})^{[13]}$ in the aspirin and ginger plus aspirin groups. Three hours after aspirin administration, all animals were anaesthetized by inhalation of ether. Blood samples were collected from the lateral canthus of the eye. Then, animals were sacrificed and stomach, kidney and liver were cleanly excised.

\section{Serum samples}

Serum samples were obtained and biochemical parameters were determined spectrophotometericaly using the available commercial kits based on the specific method for every parameters: AST and ALT according to Schumann and Klauke ${ }^{[14]}$, creatinine according to Sabbagh et al., ${ }^{[15]}$, urea based on method of Tabacco et al., ${ }^{[16]}$, uric acid according to Fossoti et al., ${ }^{[17]}$.

\section{Tissue samples}

The stomach, liver as well as kidney were immediately excised, washed several times from blood by ice-cold isotonic saline. They were dissected from any adhering connective tissue weighed and shock-freeze in liquid nitrogen $\left(-170^{\circ} \mathrm{C}\right)$ and stored at $-80^{\circ} \mathrm{C}$. The specimens were homogenized individually with tissue homogenizer to make $10 \%$ of homogenate. The homogenates were prepared for analysis by centrifugation at $18000 \mathrm{rpm}$ $\left(4^{\circ} \mathrm{C}\right)$ for $30 \mathrm{~min}$ and the supernatant was kept at $-20^{\circ} \mathrm{C}$ for analysis of oxidative stress markers including Lipid Peroxidation (LP), Superoxide Dismutase (SOD) and catalase (CAT).

\section{Analysis of oxidative stress}

The amount of malondialdehyde (MDA) in tissue homogenate of stomach, liver and kidney as an indicator of LP was determined according to Ohkawa et al., ${ }^{[18]}$ based on the reaction with thiobarbituric acid. SOD activity was estimated as described by Marklund et al., ${ }^{[19]}$ based on inhibiting pyrogallol autoxidation by SOD. The activity of SOD in tissue is directly proportional to the inhibition rate. CAT was assayed based on Aebei's $\operatorname{method~}^{[20]}$.

\section{Histopathology}

Specimens from stomach, liver and kidney were collected from all experimental and control groups and fixed in $10 \%$ neutral buffered formalin, dehydrated in ascending concentrations of ethyl alcohol (70-100\%) and then prepared using standard procedures for Hematoxylin and Eosin (H\&A) stain as described by Bancroft et la., ${ }^{[21]}$.

\section{Statistical analysis}

Statistical analysis was done by Graphpad prism V5. Statistical analysis was performed using one-way analysis of variance (ANOVA) to compare the inter- and intra-group findings. The values depicting $\mathrm{p}<0.05$ were considered as statistically significant.

\section{Results}

\section{Biochemical findings}

The results presented in Table (1) showed that serum transaminases (ALT and AST) as well as kidney function biomarkers (creatinine, urea and uric acid) have a highly significant increase $(p \leq 0.001)$ in aspirin intoxicated group compared to control group. On the other hand, pretreatment with ginger decreased significantly $(p \leq 0.001)$ these biomarkers compared to aspirin intoxicated group and maintained them close to normal levels recorded from the control group. Figure 1 demonstrated significant $(p \leq 0.001)$ reduction in the level of the anti-oxidant enzymes (SOD and CAT) but significantly increased (MDA) assayed in homogenates of stomach, kidney and liver taken from aspirin intoxicated animals compared to control group. Conversely, administration of ginger prior to aspirin preserved the anti-oxidant capacity reflected by a highly significant $(p \leq 0.001)$ increase in the levels of SOD and CAT accompanied by reduction in MDA concentrationn in the three organs.

\section{Histopathological findings}

The light microscope findings are demonstrated in Figure 2, organs are top horizontal and groups are left vertical. In rats treated with aspirin group (A), Glandular stomach showed diffuse widespread ulcer with very clear damage to the mucosal surface and surrounded by overhanging gastric mucosal margins. The base of the lesion is completely denuded of epithelium, and even the underlying muscularis mucosae; the sub-mucosa is completely exposed with marked congestion of the submucosal blood vessels in addition to infiltration of eosinophils and mast cells. Additionally, Kidney's section of the same group showed congestion of glomerular tufts as well as congestion of peritubular blood capillaries and proliferation of the intimal layers of the renal blood vessels with prominent endothelial cells. Lining epithelium of the renal tubules demonstrated different degenerative changes as papillary necrosis in the proximal convoluted tubules and vacuolar degeneration. Vacuolation of lining epithelium was consistent with hydropic or fatty change. Also, Liver tissue from (A) group revealed congestion of the central vein and blood sinusoids. Hepatocytes within the centro- 
lobular areas showed round clear vacuoles consistent to fatty changes. Pretreatment of the rats with orally administered ginger extract $(100 \mathrm{mg} / \mathrm{kg} /$ day $)$ in $(\mathrm{A}+\mathrm{G})$ group significantly reduced gastric lesion developed due to aspirin administration and ameliorated several pathological changes in the above-mentioned gastric mucosal lesions, surface mucosa showed erosion as well as disappearance of gastric pits. Sections from livers and kidneys of rats pretreated with ginger $(\mathrm{A}+\mathrm{G})$ showed corrective changes similar the normal limits in (C) group. Tissue sections of the three organs taken from animals given ginger alone in group $(\mathrm{G})$ showed similar to normal celluar architecture.

Table 1: Effect of ginger on liver and kidney function markers of control and experimental rats.

\begin{tabular}{|c|c|c|c|c|}
\hline parameter & Control & Aspirin & Ginger & Aspirin + Ginger \\
\hline \multicolumn{5}{|l|}{ Liver function biomarkers } \\
\hline $\mathrm{AST}(\mathrm{IU} / \mathrm{L})$ & $76.41 \pm 5.95$ & $113.2 \pm 7.61^{* * *}$ & $75.3 \pm 6.4^{\# \# \#}$ & $86.3 \pm 5.85^{\# \# \#}$ \\
\hline ALT(IU/L) & $26.1 \pm 2.1$ & $65.71 \pm 4.3^{* * *}$ & $27.8 \pm 1.89^{\# \# \#}$ & $33.3 \pm 1.88^{\# \# \#}$ \\
\hline \multicolumn{5}{|l|}{ Kidney function biomarkers } \\
\hline Creatinine $(\mathrm{mg} / \mathrm{dl})$ & $0.67 \pm 0.04$ & $1.71 \pm 0.12^{* * *}$ & $0.70 \pm 0.04^{\# \#}$ & $0.88 \pm 0.55^{\# \# \#}$ \\
\hline Urea $(\mathrm{mg} / \mathrm{dl})$ & $28.2 \pm 1.99$ & $53.97 \pm 3.3^{* * *}$ & $27.01 \pm 2.1^{\# \#}$ & $30.9 \pm 2.2^{\# \# \#}$ \\
\hline Uric acid (mg/dl) & $1.56 \pm 0.1$ & $4.65 \pm 0.33^{* * *}$ & $1.65 \pm 0.09^{\# \# \#}$ & $2.08 \pm 0.14^{\# \# \#}$ \\
\hline
\end{tabular}

All values are expressed as mean \pm standard deviation $(\mathrm{SD}), \mathrm{n}=10$ for each treatment group. ${ }^{* * *} p<0.001$ is highly significant different from control group; ${ }^{\# \#} p<0.001$ is highly significant different from aspirin treated group.
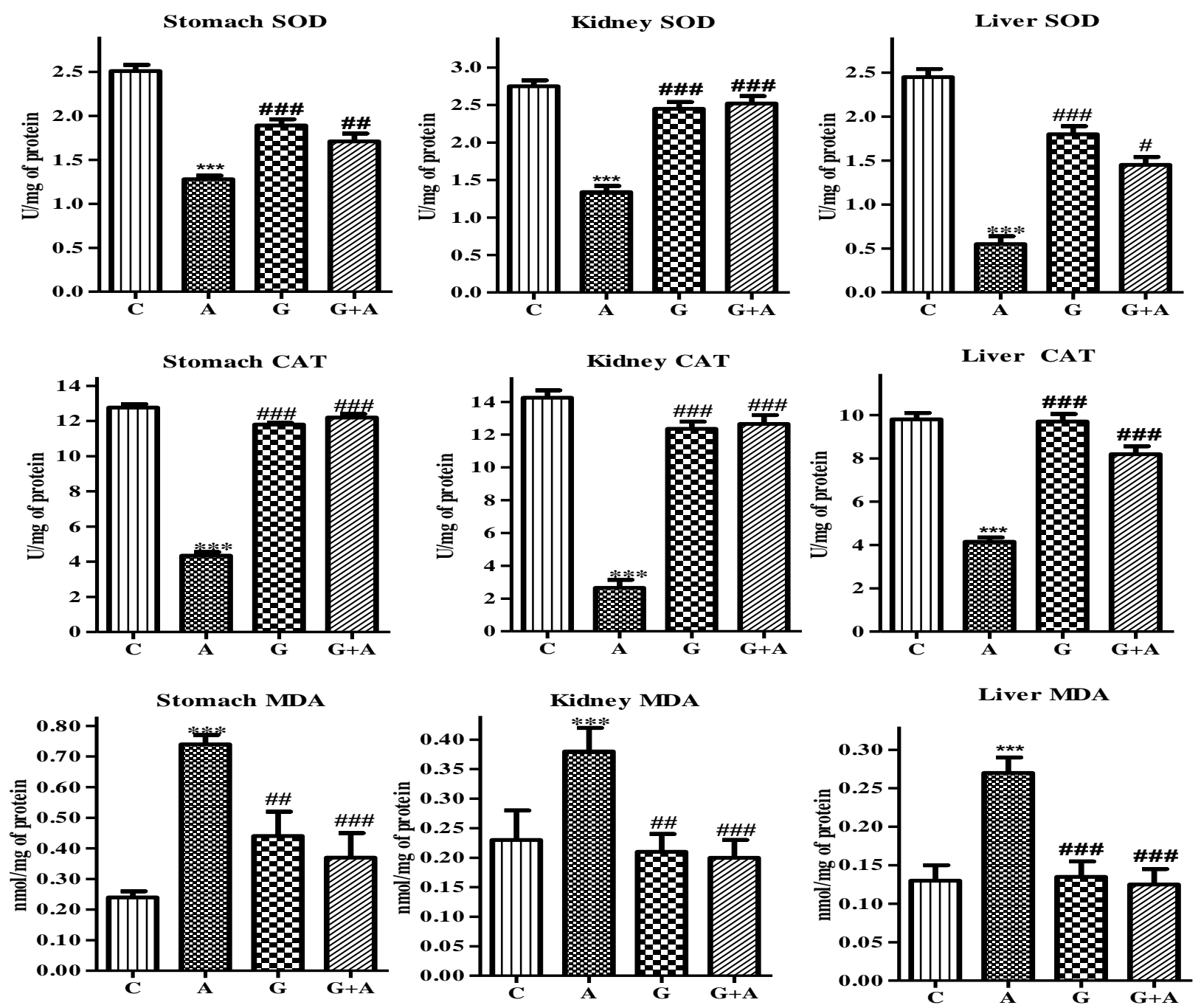

Fig. 1: Activities of SOD and CAT and MDA level in homogenates of stomach liver and kidney in control (C), Aspirin treated $(\mathrm{A})$, Ginger treated $(\mathrm{G})$ and Aspirin and Ginger co-treated $(\mathrm{G}+\mathrm{A})$. Values are the mean of 8 measurements $\pm \mathrm{SD}$. ${ }^{* * *} \mathrm{p} \leq 0.001$ compared to control group (C), \#\#p $\leq 0.01$ compared to treated group (A), \#\#\# $\leq 0.001$ compared to treated group (A). 


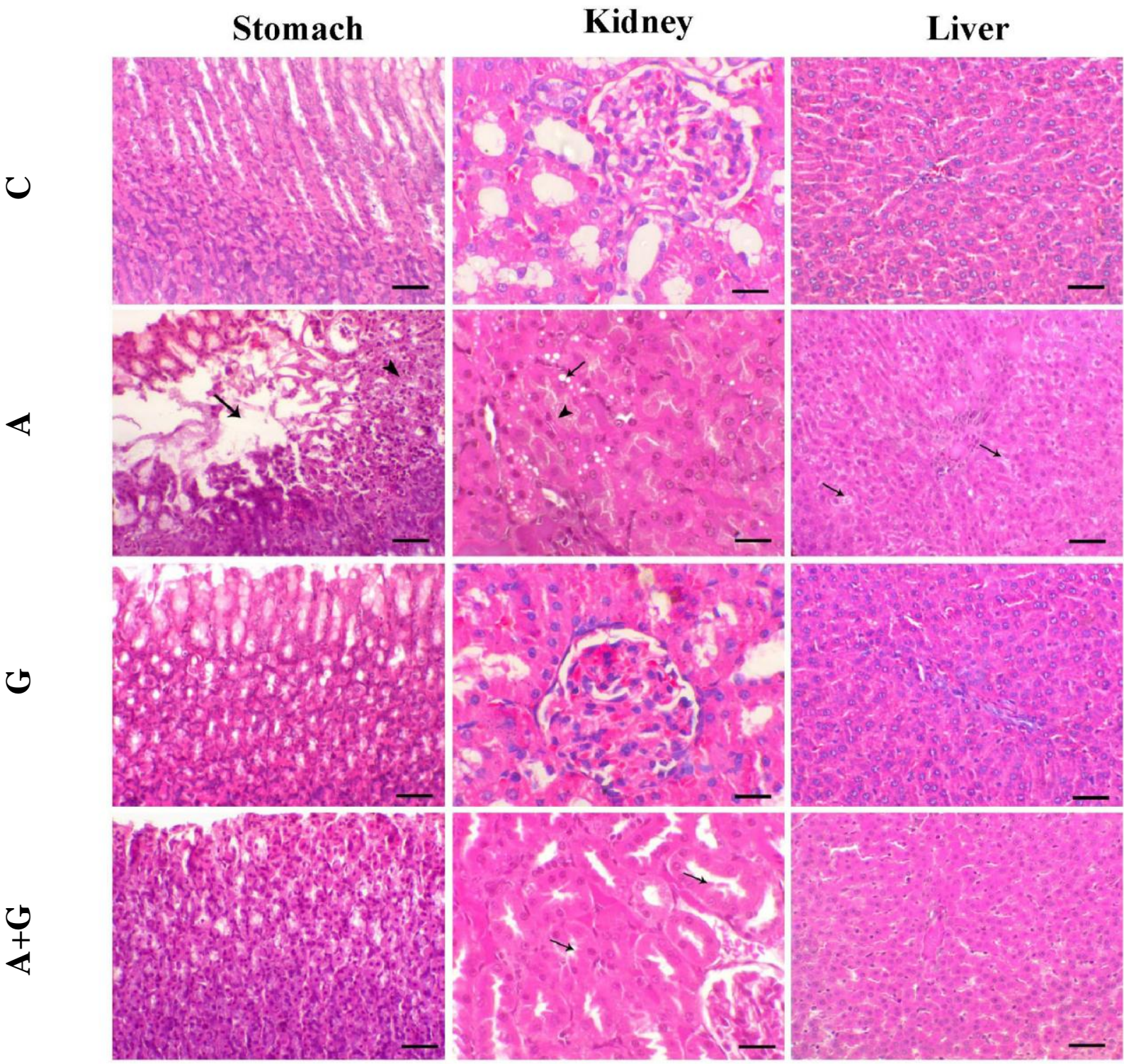

Fig. 2: Histopathological observations in homogenates of stomach liver and kidney in control (C), Aspirin treated (A), Ginger treated (G) and Aspirin and Ginger co-treated $(\mathbf{A}+\mathbf{G})$. The $1^{\text {st }}$ upper lane of the photomicrographs obtained from control animal showing normal gastric mucosa, kidney and liver of control animal. The $2^{\text {nd }}$ lane of the photomicrographs obtained from aspirin-treated animal showing the ulcerated gastric mucosa (arrow) accompanied with severe degeneration of the gland, renal papillary necrosis (arrowhead) and fatty changes within the renal tubular epithelial lining and marked diffuse hepatic vacuolation. The $3^{\text {rd }}$ lane of control animal treated with ginger showing normal gastric, renal and hepatic structures. The $4^{\text {th }}$ lane of animal treated with $\mathrm{A}+\mathrm{G}$ revealing mild degeneration of the gastric glands and renal and hepatic tissues were within normal limits. H\&E stain, Bar $=100 \mu \mathrm{m}$.

\section{Discussion:}

The aim of the present study is to assess the potential protective effect of ginger on aspirin adverse effects on stomach, kidney and liver. Based on the data obtainedfrom the current study, there is a significant increase in serum renal function biomarkers, creatinine, urea and uric acid, which is in agreement with previous records ${ }^{[22-24]}$. Interestingly, the pathomechanism of aspirin induced nephropathy seems similar to its gastropathy and is due to direct toxicity ${ }^{[25,26]}$ or to ischemia resulting from prostaglandin (PGE2) inhibitory effect of aspirin ${ }^{[27]}$. Similar to stomach, PGE2 produced by the kidney is important to sustain optimum blood flow to the kidney. Decreased PGE2 concentration by aspirin causes reduction in blood flow. Since the renal cortex (outside) is the first destination of blood and renal medulla (inside) is the second one, the deeper structures of the kidney are most affected by reduced blood flow. Consequently, the innermost structures of the kidney, the renal papillae, are especially dependent on PGE2 synthesis to maintain adequate blood flow. Inhibition of PGE2 production therefore rather selectively damages the renal papillae, increasing the risk of renal papillary necrosis ${ }^{[28,29]}$.

Our results of renal function tests carried out for cotreated group (Aspirin and ginger) showed significant 
reduction in creatinine, urea and uric acid levels compared with those of aspirin treated animals. The results demonstrated close to normal kidney functions, which were consistent with Mehrdad et al., [30] who stated that ginger has a beneficial effect for removal of urea and creatinine from plasma and considered as a therapeutic herb to manage renal function. The corrective histopathological findings after treatment with ginger extracts give an additional support that ginger mops up free radicals generation by aspirin, reduces inflammation, improves kidney function, and induces healthy state of renal cells, suggesting its significant role as renal protective agent. This was attributed to their enormous concentrations of natural antioxidants: flavonoids, sterols, and alkaloids. In harmony with our results, ginger showed a potential defensive role against renal ischemia ${ }^{[31]}$, renal damage induced by alcohol intoxication [32], and renal toxicity induced by doxorubicin ${ }^{[33]}$.

The data obtained from liver function tests of aspirin intoxicated animals revealed significant elevation of serum transaminases (ALT, AST) in consistency with previous reports ${ }^{[34]}$ indicating damage of hepatic tissue. Consequently, Aspirin hepatotoxicity is demonstrated in light microscopic findings showing degenerative changes of patchy necrosis with substantial periportal infiltration of inflammatory cells including eosinophil, mast cells and lymphocytes typically as described by Prescott ${ }^{[35]}$. Additionally, the investigation of hepatic tissue homogenate showed increased lipid peroxidation marker (MDA) but decreased antioxidant enzymes (SOD and CAT) in agreement with previous records ${ }^{[36]}$ indicating severe oxidative stress as a result of the acute hepatitis. On the other hand, serum samples from ginger and aspirin co-treated animals revealed close to normal values of transaminases (ALT and AST) confirmed by corrective changes on hepatic tissue sections of the same animals when examined by light microscope. The reported results seem to be similar to those recorded by ${ }^{[37,38]}$. Also, the anti-oxidant capacity of ginger was demonstrated as recovery of hepatic redox parameters. Surprisingly, ginger has prostaglandin inhibitory effect the same like aspirin ${ }^{[39,40]}$. However, it will not be a surprise if downstream effects of both aspirin and ginger are explained. While aspirin chemopreventive effect is mediated through inhibition of cyclooxygenases increasing the susceptibility of cancer cells to apoptosis [41] aspirin showed a cyclooxygenase-independent mechanism during apoptosis signaling ${ }^{[42]}$. Furthermore, proapooptotic role along with antitumor effect of aspirin are mediated through activation of $\mathrm{NF}-\kappa \mathrm{B}$ and induction of oxidative stress ${ }^{[43]}$. As already reported, apoptosis is initiated through the phenomenon of mitochondrial permeability transition (MPT) that can induce loss of mitochondrial membrane potential, oxidative stress, and a decrease in ATP production upon pathological activation ${ }^{[44]}$. Battaglia et al., ${ }^{[45]}$ demonstrated that induction of MPT by salicylate is the result of oxidative stress. On the other side, ginger demonstrated whole body protection against oxidative stress [46] including inhibition of submolecular pathways such as NF- $\kappa$ B [46,47]

The histopathological results of the current work demonstrated that aspirin oral administration led to remarkable ulcers in the glandular area of the stomach excised from aspirin treated rats compared with other animals. The observations are in harmony with previous study demonstrating that aspirin can produce marked ulcers in rats ${ }^{[13]}$. Underlying mechanism of aspirin induced gastric ulcer, like other NSAIDs, looks complicated and multifactorial. Nevertheless, Aspirin effects could be classified to systemic and topic. The classical systemic mechanism stated that aspirin induces ulcer through reduction of synthesis of PGE2s ${ }^{[\mathbf{4 8 , 4 9 ]}}$ and increasing NO levels ${ }^{[50]}$. The optimum gastric blood flow is mainly maintained by normal levels of PGE2s and NO ${ }^{[51,52]}$, which supports the integrity of the gastric mucosa and its adaptation for chronic aspirin intake ${ }^{[53]}$. Moreover, aspirin injured mucosal tissue appeared with significant granulocytes infiltration. Accumulation of mast cells and eosinophils were observed before with aspirin induced gastric ulcer model ${ }^{[54]}$. Mast cells aggregation is due to aspirin reduced PGE2 levels. Additionally, Mast cells produce high levels of histamine that initiates gastric mucosal injury ${ }^{[5]}$. Also, observation of high count of neutrophil is supported by previous workers ${ }^{[56,57]}$, which signified the neutrophil dependent microvascular injury in initiation of aspirin induced gastric ulcer. Furthermore, aspirin induced gastropathy could be attenuated by inhibition of neutrophil accumulation ${ }^{[\mathbf{5 6 , 5 8}]}$. What is more, administration of TNF- $\alpha$ inhibitors attenuates aspirin and other NSAIDs induced gastric ulcer ${ }^{[56,59]}$. TNF- $\alpha$ increases neutrophilderived superoxide generation ${ }^{[60]}$ and stimulates IL-1 production, leading to neutrophil infiltrations ${ }^{[\mathbf{6 1 , 6 2}]}$. By this means, reactive oxygen species (ROS) play an important role in pathomechanism of aspirin induced gastric ulcer ${ }^{[63]}$. The results of the present study revealed significant reduction in the gastric antioxidant enzymes, SOD and CAT similar to previous records ${ }^{[38]}$. In contrast, MDA, the indicator of lipid peroxidation showed significant high levels. As suggested before, gastric ulcer could be due to attenuation of mucosal antioxidant mechanisms and augmentation of lipid peroxidation ${ }^{[60]}$. Surprisingly, aspirin has the capacity to induce gastric ulcer if it is administered orally unlike other NSAIDS such as indomethacin which cause injury regardless of route of administration emphasizing the importance of topical injury in aspirin-induced ulcers ${ }^{[64]}$. In Co-treated animals (ginger and aspirin) the histopatholgical findings revealed gastric mucosa with close to normal architectures. The anti-ulcerative effects of ginger have previously been investigated in experimental gastric ulcer models ${ }^{[65-67]}$. However, the mechanism underlying the protective effects of ginger against gastric damage is unclear. From our results, ginger powder is likely to protect the stomach against aspirin induced ulcer by improving mucosal blood flow ${ }^{[13]}$ 
reducing iNOS activity in the gastric mucosa ${ }^{[13,50]}$ and inflammatory cytokines (TNF and IL-1) expression [68,69]. These effects of ginger powder could to be attributable to the main ingredients of ginger, gingerol and shogaol ${ }^{[69]}$. In the meantime, results of oxidative stress markers were reversed after oral administration of ginger extract with aspirin. Ginger enhanced SOD and activity, and reduced MDA level, which seems in agreement with previous studies ${ }^{\text {[0-72] }}$.

In the present study, light microscopic lesion of renal tissues collected from aspirin treated animals demonstrated the well-defined lesions of papillary necrosis and cortical interstitial nephritis, the typical lesion associated with abuse of aspirin ${ }^{[73]}$.

\section{Conclusion}

Based on the data obtained from the current study, it could be suggested that oral administration of ginger powder has antioxidant capacity to protect stomach, kidney and liver against aspirin induced injury mainly by boosting antioxidant enzymes and inhibiting lipid peroxidation. Taken together, ginger could be the supplement when aspirin is the drug of choice as antiplatelet aggregation.

\section{References}

1) Lewis, H. D., Jr., Davis, J. W., Archibald, D. G., Steinke, W. E., Smitherman, T. C., Doherty, J. E., 3rd, Schnaper, H. W., LeWinter, M. M., Linares, E., Pouget, J. M., Sabharwal, S. C., Chesler, E. and DeMots, H. (1983). Protective effects of aspirin against acute myocardial infarction and death in men with unstable angina. Results of a Veterans Administration Cooperative Study. N Engl J Med. 309(7):396-403.

2) Yang, F., Jiang, W., Bai, Y., Han, J., Liu, X., Zhang, G. and Zhao, G. (2015). Treatment of Rivaroxaban versus Aspirin for Non-disabling Cerebrovascular Events (TRACE): study protocol for a randomized controlled trial. BMC Neurol. 15(1): 195 .

3) McLaughlin, J. K., Lipworth, L., Chow, W. H. and Blot, W. J. (1998). Analgesic use and chronic renal failure: a critical review of the epidemiologic literature. Kidney Int. 54(3):679-86.

4) Andrade, R. J., Lucena, M. I., Fernandez, M. C., Pelaez, G., Pachkoria, K., Garcia-Ruiz, E., Garcia-Munoz, B., Gonzalez-Grande, R., Pizarro, A., Duran, J. A., Jimenez, M., Rodrigo, L., Romero-Gomez, M., Navarro, J. M., Planas, R., Costa, J., Borras, A., Soler, A., Salmeron, J. and Martin-Vivaldi, R. (2005). Drug-induced liver injury: an analysis of 461 incidences submitted to the Spanish registry over a 10-year period. Gastroenterology. 129(2):512-521.

5) Hussaini, S. H. and Farrington, E. A. (2007). Idiosyncratic drug-induced liver injury: an overview. Expert Opin Drug Saf. 6(6):673-684.

6) Bjornsson, E. (2010). Review article: drug-induced liver injury in clinical practice. Aliment Pharmacol Ther. 32(1):3-13.
7) Zaffanello, M., Brugnara, M., Angeli, S. and Cuzzolin, L. (2009). Acute non-oliguric kidney failure and cholestatic hepatitis induced by ibuprofen and acetaminophen: a case report. Acta Paediatr. 98(5):903-905.

8) Tomaszewski, M., Zukowska-Szczechowska, E., Zywiec, J. and Grzeszczak, W. (2001). Transient anuria in a patient with chronic renal failure and liver affection after a single oral dose of diclofenac. Nephron. 88(3):287-288.

9) Ahmad, B., Rehman, M. U., Amin, I., Arif, A., Rasool, S., Bhat, S. A., Afzal, I., Hussain, I., Bilal, S. and Mir, M. (2015). A Review on Pharmacological Properties of Zingerone (4-(4Hydroxy-3-methoxyphenyl)-2-butanone). Scientific World Journal: p. 816364.

10) Rajan, I., Narayanan, N., Rabindran, R., Jayasree, P. R. and Manish Kumar, P. R. (2013). Zingerone protects against stannous chlorideinduced and hydrogen peroxide-induced oxidative DNA damage in vitro. Biol Trace Elem Res. 155(3): 455-459.

11) Kim, M. K., Chung, S. W., Kim, D. H., Kim, J. M., Lee, E. K., Kim, J. Y., Ha, Y. M., Kim, Y. H., No, J. K., Chung, H. S., Park, K. Y., Rhee, S. H., Choi, J. S., Yu, B. P., Yokozawa, T., Kim, Y. J. and Chung, H. Y. (2010). Modulation of agerelated NF-kappaB activation by dietary zingerone via MAPK pathway. Exp Gerontol. 45(6):419-426.

12) Vinothkumar, R., Sudha, M. and Nalini, N. (2014). Chemopreventive effect of zingerone against colon carcinogenesis induced by 1,2dimethylhydrazine in rats. Eur $\mathrm{J}$ Cancer Prev. 23(5):361-371.

13) Wang, Z., Hasegawa, J., Wang, X., Matsuda, A., Tokuda, T., Miura, N. and Watanabe, T. (2011). Protective Effects of Ginger against Aspirin-Induced Gastric Ulcers in Rats. Yonago Acta Med. 54(1):119.

14) Schumann, G. and Klauke, R. (2003). New IFCC reference procedures for the determination of catalytic activity concentrations of five enzymes in serum: preliminary upper reference limits obtained in hospitalized subjects. Clin Chim Acta. 327(1-2): 69-79.

15) Sabbagh, M., Rick, W. and Schneider, S. (1988). A kinetic method for the direct determination of creatinine in serum with 3,5-dinitrobenzoic acid without deproteinization. J Clin Chem Clin Biochem. 26(1):15-24.

16) Tabacco, A., Meiattini, F., Moda, E. and Tarli, P. (1979). Simplified enzymic/colorimetric serum urea nitrogen determination. Clin Chem. 25(2):336-337.

17) Fossati, P., Prencipe, L. and Berti, G. (1980). Use of 3,5-dichloro-2-hydroxybenzenesulfonic acid/4aminophenazone chromogenic system in direct enzymic assay of uric acid in serum and urine. Clin Chem. 26(2):227-231. 
18) Ohkawa, H., Ohishi, N. and Yagi, K. (1979). Assay for lipid peroxides in animal tissues by thiobarbituric acid reaction. Anal Biochem. 95(2): 351-358.

19) Marklund, S. L. (1985). Superoxide dismutase isoenzymes in tissues and plasma from New Zealand black mice, nude mice and normal BALB/c mice. Mutat Res. 148(1-2):129-134.

20) Aebi, H. (1984). Catalase in vitro. Methods Enzymol. 105:121-126.

21) Bancroft, J. D., Stevens, A. and Turner, D. R. (1996). Theory and Practice of Histological techniques. Fourth edition. Churchill Livingstone, NewYork.

22) Murray, T.G. and Goldberg, M. (1978). Analgesic-associated nephropathy in the U.S.A.: epidemiologic, clinical and pathogenetic features. Kidney Int. 13(1):64-71.

23) Dixit, M. P., Nguyen, C., Carson, T., Guedes, B., Dixit, N. M., Bell, J. M. and Wang, Y. (2008). Non-steroidal anti-inflammatory drugs-associated acute interstitial nephritis with granular tubular basement membrane deposits. Pediatr Nephrol. 23(1):145-148.

24) Yildiz, B. S., Ozkan, E., Esin, F., Alihanoglu, Y. I., Ozkan, H., Bilgin, M., Kilic, I. D., Ergin, A., Kaftan, H. A. and Evrengul, H. (2016). Does high serum uric acid level cause aspirin resistance? Blood Coagul Fibrinolysis. 27(4):412-418.

25) Robinson, M. J., Nichols, E. A. and Taitz, L. (1967). Nephrotoxic effect of acute sodium salicylate intoxication in the rat. Arch Pathol. 84(3):224-226.

26) Anandan, J. V. and Matzke, G. R. (1981). Nephropathy as a hazard of analgesic abuse. Am J Hosp Pharm. 38(10):1536-1539.

27) Kincaid-Smith, P., Saker, B. M., McKenzie, I. F. and Muriden, K. D. (1968). Lesions in the blood supply of the papilla in experimental analgesic nephropathy. Med J Aust. 1(6):203-206.

28) Spuhler, O. and Zollinger, H. U. (1953). Chronic interstitial nephritis]. Z Klin Med. 151(1):1-50.

29) Norregaard, R., Jensen, B. L., Topcu, S. O., Wang, G., Schweer, H., Nielsen, S. and Frokiaer, J. (2010). Urinary tract obstruction induces transient accumulation of COX-2-derived prostanoids in kidney tissue. Am J Physiol Regul Integr Comp Physiol. 298(4):R1017-25.

30) Mehrdad, M., Messripour, M. and Ghobadipour, M. (2007). The effect of ginger extract on blood urea nitrogen and creatinine in mice. Pak J Biol Sci. 10(17):2968-2971.

31) Maghsoudi, S., Gol, A., Dabiri, S. and Javadi, A. (2011). Preventive effect of ginger (Zingiber officinale) pretreatment on renal ischemiareperfusion in rats. Eur Surg Res. 46(1):45-51.

32) Shanmugam, K. R., Ramakrishna, C. H., Mallikarjuna, K. and Reddy, K. S. (2010). Protective effect of ginger against alcohol-induced renal damage and antioxidant enzymes in male albino rats. Indian J Exp Biol. 48(2):143-149.

33) Ajith, T. A., Aswathy, M. S. and Hema, U. (2008). Protective effect of Zingiber officinale roscoe against anticancer drug doxorubicin-induced acute nephrotoxicity. Food Chem Toxicol. 46(9):31783181.

34) Bernstein, B. H., Singsen, B.H., King, K. K. and Hanson, V. (1977). Aspirin-induced hepatotoxicity and its effect on juvenile rheumatoid arthritis. Am J Dis Child. 131(6):659-663.

35) Prescott, L. F. (1980). Hepatotoxicity of mild analgesics. Br J Clin Pharmacol. 10(2):373S-379S.

36) Bouzenna, H., Samout, N., Amani, E., Mbarki, S., Tlili, Z., Rjeibi, I., Elfeki, A., Talarmin, H. and Hfaiedh, N. (2016). Protective Effects of Pinus halepensis L. Essential Oil on Aspirin-induced Acute Liver and Kidney Damage in Female Wistar Albino Rats. J Oleo Sci. 65(8):701-712.

37) Abdulaziz Bardi, D., Halabi, M. F., Abdullah, N. A., Rouhollahi, E., Hajrezaie, M. and Abdulla, M. A. (2013). In vivo evaluation of ethanolic extract of Zingiber officinale rhizomes for its protective effect against liver cirrhosis. Biomed Res Int.:918460.

38) Zaghlool, S. S., Shehata, B. A., Abo-Seif, A. A. and Abd El-Latif, H. A. (2015). Protective effects of ginger and marshmallow extracts on indomethacin-induced peptic ulcer in rats. $\mathrm{J}$ Nat Sci Biol Med. 6(2):421-428.

39) Jiang, Y., Turgeon, D. K., Wright, B. D., Sidahmed, E., Ruffin, M. T., Brenner, D. E., Sen, A. and Zick, S. M. (2013). Effect of ginger root on cyclooxygenase-1 and 15-hydroxyprostaglandin dehydrogenase expression in colonic mucosa of humans at normal and increased risk for colorectal cancer. Eur J Cancer Prev. 22(5):455-460.

40) Zick, S. M., Turgeon, D. K., Ren, J., Ruffin, M. T., Wright, B. D., Sen, A., Djuric, Z. and Brenner, D. E. (2015). Pilot clinical study of the effects of ginger root extract on eicosanoids in colonic mucosa of subjects at increased risk for colorectal cancer. Mol Carcinog. 54(9):908-915.

41) Sheng, H., Shao, J., Morrow, J. D., Beauchamp, R. D. and DuBois, R. N. (1998). Modulation of apoptosis and Bcl-2 expression by prostaglandin E2 in human colon cancer cells. Cancer Res. 58(2):362366.

42) Rigas, B. and Shiff, S. J. (2000). Is inhibition of cyclooxygenase required for the chemopreventive effect of NSAIDs in colon cancer? A model reconciling the current contradiction. Med Hypotheses. 54(2):210-215.

43) Huang, L., Wong, C. C., Mackenzie, G. G., Sun, Y., Cheng, K. W., Vrankova, K., Alston, N., Ouyang, N. and Rigas, B. (2014). Phospho-aspirin (MDC-22) inhibits breast cancer in preclinical animal models: an effect mediated by EGFR inhibition, p53 acetylation and oxidative stress. BMC Cancer. 14:141. 
44) Perez, M. J. and Quintanilla, R. A. (2017). Development or disease: duality of the mitochondrial permeability transition pore. Dev Biol., 426(1):1-7.

45) Battaglia, V., Salvi, M. and Toninello, A. (2005). Oxidative stress is responsible for mitochondrial permeability transition induction by salicylate in liver mitochondria. J Biol Chem. 280(40):3386433872.

46) Prasad, S. and Tyagi, A. K. (2015). Ginger and its constituents: role in prevention and treatment of gastrointestinal cancer. Gastroenterol Res Pract.: 142979.

47) Kim, Y., Kim, D. M. and Kim, J. Y. (2017). Ginger Extract Suppresses Inflammatory Response and Maintains Barrier Function in Human Colonic Epithelial Caco-2 Cells Exposed to Inflammatory Mediators. J Food Sci. 82(5):1264-1270.

48) Takeuchi, K., Ueki, S. and Tanaka, H. (1986). Endogenous prostaglandins in gastric alkaline response in the rat stomach after damage. Am $\mathrm{J}$ Physiol. 250(6 Pt 1):G842-849.

49) Wang, X. S., Wu, A. Y., Leung, P. S. and Lau, H. Y. (2007). PGE suppresses excessive anti-IgE induced cysteinyl leucotrienes production in mast cells of patients with aspirin exacerbated respiratory disease. Allergy. 62(6):620-627.

50) Konturek, P. C., Kania, J., Hahn, E. G. and Konturek, J. W. (2006). Ascorbic acid attenuates aspirin-induced gastric damage: role of inducible nitric oxide synthase. J Physiol Pharmacol. 57(5):125-136.

51) Brzozowski, T., Konturek, P. C., Konturek, S. J., Brzozowska, I. and Pawlik, T. (2005). Role of prostaglandins in gastroprotection and gastric adaptation. J Physiol Pharmacol. 56(5):33-55.

52) Pawlik, M., Ptak, A., Pajdo, R., Konturek, P. C., Brzozowski, T. and Konturek, S. J. (2001). Sensory nerves and calcitonin gene related peptide in the effect of ischemic preconditioning on acute and chronic gastric lesions induced by ischemiareperfusion. J Physiol Pharmacol. 52(4 Pt 1):569581.

53) Whittle, B. J., Lopez-Belmonte, J. and Moncada, S. (1990). Regulation of gastric mucosal integrity by endogenous nitric oxide: interactions with prostanoids and sensory neuropeptides in the rat. $\mathrm{Br}$ J Pharmacol. 99(3):607-611.

54) Mutmainah, Susilowati, R., Rahmawati, N. and Nugroho, A. E. (2014). Gastroprotective effects of combination of hot water extracts of turmeric (Curcuma domestica L.), cardamom pods (Ammomum compactum S.) and sembung leaf (Blumea balsamifera DC.) against aspirin-induced gastric ulcer model in rats. Asian Pac J Trop Biomed. 4(1):S500-4.

55) Reimann, H. J., Lewin, J., Schmidt, U., Wendt, P., Blueml, G. and Dajani, E. Z. (1987). Misoprostol prevents damage to the gastric mucosa by stabilizing the mast cells. Prostaglandins. 33:105116.

56) Naito, Y., Yoshikawa, T., Yagi, N., Matsuyama, K., Yoshida, N., Seto, K. and Yoneta, T. (2001). Effects of polaprezinc on lipid peroxidation, neutrophil accumulation, and TNF-alpha expression in rats with aspirin-induced gastric mucosal injury. Dig Dis Sci. 46(4):845-851.

57) Wallace, J. L., Keenan, C. M. and Granger, D. N. (1990). Gastric ulceration induced by nonsteroidal anti-inflammatory drugs is a neutrophil-dependent process. Am J Physiol. 259(3 Pt 1):G462-467.

58) Yoshida, N., Yoshikawa, T., Nakamura, Y., Arai, M., Matsuyama, K., Iinuma, S., Nishimura, S. and Kondo, M. (1995). Role of neutrophilendothelial cell interactions in gastric mucosal injury induced by aspirin. J Clin Gastroenterol. 21(1):S7377.

59) Santucci, L., Fiorucci, S., Giansanti, M., Brunori, P. M., Di Matteo, F. M. and Morelli, A. (1994). Pentoxifylline prevents indomethacin induced acute gastric mucosal damage in rats: role of tumour necrosis factor alpha. Gut. 35(7):909-915.

60) Kwiecien, S., Brzozowski, T. and Konturek, S. J. (2002). Effects of reactive oxygen species action on gastric mucosa in various models of mucosal injury. J Physiol Pharmacol. 53(1):39-50.

61) Kokura, S., Wolf, R. E., Yoshikawa, T., Granger, D. N. and Aw, T. Y. (2000). T-lymphocyte-derived tumor necrosis factor exacerbates anoxiareoxygenation-induced neutrophil-endothelial cell adhesion. Circ Res. 86(2):205-213.

62) Odashima, M., Otaka, M., Jin, M., Komatsu, K., Wada, I., Horikawa, Y., Matsuhashi, T., Hatakeyama, N., Oyake, J., Ohba, R., Watanabe, S. and Linden, J. (2006). Attenuation of gastric mucosal inflammation induced by aspirin through activation of A2A adenosine receptor in rats. World J Gastroenterol. 12(4):568-573.

63) Pohle, T., Brzozowski, T., Becker, J. C., Van der Voort, I. R., Markmann, A., Konturek, S. J., Moniczewski, A., Domschke, W. and Konturek, J. W. (2001). Role of reactive oxygen metabolites in aspirin-induced gastric damage in humans: gastroprotection by vitamin C. Aliment Pharmacol Ther. 15(5):677-687.

64) Mashita, Y., Taniguchi, M., Yokota, A., Tanaka, A. and Takeuchi, K. (2006). Oral but not parenteral aspirin upregulates $\mathrm{COX}-2$ expression in rat stomachs. a relationship between COX-2 expression and PG deficiency. Digestion. 73(2-3):124-132.

65) Yamahara, J., Mochizuki, M., Rong, H. Q., Matsuda, H. and Fujimura, H. (1988). The antiulcer effect in rats of ginger constituents. J Ethnopharmacol. 23(2-3):299-304.

66) al-Yahya, M. A., Rafatullah, S., Mossa, J. S., Ageel, A. M., Parmar, N. S. and Tariq, M. (1989). Gastroprotective activity of ginger zingiber officinale rosc., in albino rats. Am J Chin Med. 17(1-2):51-56. 
67) Khushtar, M., Kumar, V., Javed, K. and Bhandari, U. (2009). Protective Effect of Ginger oil on Aspirin and Pylorus Ligation-Induced Gastric Ulcer model in Rats. Indian J Pharm Sci. 71(5):554558.

68) Isa, Y., Miyakawa, Y., Yanagisawa, M., Goto, T., Kang, M. S., Kawada, T., Morimitsu, Y., Kubota, K. and Tsuda, T. (2008). 6-Shogaol and 6gingerol, the pungent of ginger, inhibit TNF-alpha mediated downregulation of adiponectin expression via different mechanisms in 3T3-L1 adipocytes. Biochem Biophys Res Commun. 373(3):429-434.

69) Lantz, R. C., Chen, G. J., Sarihan, M., Solyom, A. M., Jolad, S. D. and Timmermann, B. N. (2007). The effect of extracts from ginger rhizome on inflammatory mediator production. Phytomedicine. 14(2-3):123-128.
70) Ko, J. K. and Leung, C. C. (2010). Ginger extract and polaprezinc exert gastroprotective actions by anti-oxidant and growth factor modulating effects in rats. J Gastroenterol Hepatol. 25(12):1861-1868.

71) Hamed, M. A., Ali, S. A. and El-Rigal, N. S. (2012). Therapeutic potential of ginger against renal injury induced by carbon tetrachloride in rats. Scientific World Journal:840421.

72) Nanjundaiah, S. M., Annaiah, H. N. and Dharmesh, S. M. (2011). Gastroprotective Effect of Ginger Rhizome (Zingiber officinale) Extract: Role of Gallic Acid and Cinnamic Acid in $\mathrm{H}(+), \mathrm{K}(+)-$ ATPase/H. pylori Inhibition and Anti-Oxidative Mechanism. Evid Based Complement Alternat Med.:249487.

73) Molland, E. A. (1978). Experimental renal papillary necrosis. Kidney Int. 13(1):5-14. 